\title{
Chemical and antioxidant profiles of acorn tissues from Quercus spp.: Potential as new industrial raw materials
}

\author{
A.F. Vinha ${ }^{\mathrm{a}, \mathrm{b}}$, A.S.G. Costa ${ }^{\mathrm{a}}$, João C.M. Barreira ${ }^{\mathrm{a}, \mathrm{c}, *}$, R. Pacheco ${ }^{\mathrm{a}}$, M. Beatriz P.P. Oliveira ${ }^{\mathrm{a}}$ \\ a REQUIMTE/LAQV, Department of Chemical Sciences, Faculty of Pharmacy, University of Porto, Rua Jorge Viterbo Ferreira, no. 228, 4050-313 Porto, Portugal \\ ${ }^{\mathrm{b}}$ FP-ENAS (UFP Energy, Environment and Health Research Unit), CEBIMED (Biomedical Research Center), University Fernando Pessoa, Praça 9 de Abril, 349 , \\ 4249-004 Porto, Portugal \\ ${ }^{c}$ Mountain Research Centre (CIMO), ESA, Polytechnic Institute of Bragança, Campus de Santa Apolónia, 5300-253 Bragança, Portugal
}

\section{A R T I C L E I N F O}

\section{Article history:}

Received 4 May 2016

Received in revised form 12 August 2016

Accepted 13 August 2016

Available online 25 August 2016

\section{Keywords:}

Quercus spp.

Acorn tissues

Nutritional parameters

Phytochemicals

Antioxidant activity

Industrial applications

\begin{abstract}
A B S T R A C T
The bioactivity of different organs and tissues of Quercus spp. (Fagaceae), an important group of evergreen or deciduous trees from temperate and tropical climatic areas, represents a good starting point for possible industrial applications. Nevertheless, Quercus fruits, generally known as acorns, are currently undervalued and underexploited. Accordingly, the proximate composition, fatty acids and tocopherols profiles, chlorophyll, lycopene and $\beta$-carotene contents, as well as the antioxidant activity, were studied in different Quercus species to boost new applications in food, cosmetic and pharmaceutical industries. In general, significant differences were found among the nutritional parameters, fatty acids and tocopherols contents and bioactivity indicators, either considering phenotypic (studied species) or botanical (acorn tissues) factors. The acorn tissues and the Quercus species that optimize the production of each nutrient and bioactive compound, as well as that allowing the highest antioxidant activity were thoroughly identified. The obtained information provides an increased knowledge to define potential industrial applications for acorn tissues, potentially offering economic advantages to this underutilized natural resource.
\end{abstract}

(c) 2016 Elsevier B.V. All rights reserved.

\section{Introduction}

The consumption of natural resources has increased substantially, mainly due to the recent consumers' trends. This current concept is mentioned in recent studies, which report several bioactivities on different fruit tissues (Barreira et al., 2008; Vázquez et al., 2008; Baiano, 2014; Costa et al., 2014; Brizi et al., 2016). Furthermore, most natural products have low toxicity and comply with sustainability principles (Islam et al., 2013).

Currently, the potential as a food resource of Quercus spp. is being underestimated, comparatively to other plants, e.g., chestnut (Castanea sativa Mill.) (Barreira et al., 2009a; Vasconcelos et al., 2010; Barreira et al., 2012), walnut (Juglans regia L.) (Amaral et al., 2005; Liao et al., 2016) and hazelnut (Corylus avellana L.) (Amaral et al., 2006; Li and Parry, 2011). Acorns are abundant in the Portuguese territory, occupying 1107600 ha, an area much higher than that dedicated to chestnut ( $\sim 1100 \mathrm{ha}$ ) and almond ( $36530 \mathrm{ha})$.

\footnotetext{
* Corresponding author at: REQUIMTE/LAQV, Department of Chemical Sciences, Faculty of Pharmacy, University of Porto, Rua Jorge Viterbo Ferreira, no. 228, 4050313 Porto, Portugal.

E-mail address: jbarreira@ipb.pt (J.C.M. Barreira).
}

Even so, the inclusion of acorns in human nutrition is still scarce (Cantos et al., 2003; Tejerina et al., 2011; INE, 2014).

Acorns were previously reported as having high contents in starch (48-50\%) and low levels of proteins and fat content (circa $2 \%$ in both cases) (Deforce et al., 2009). Despite not being as nutritionally rich as other common nuts, acorns represent good alternatives to other high-starch content products, such as chestnuts or potatoes. Furthermore, acorn oil also presents relevant features to be considered for industrial purposes, containing mainly oleic and linoleic acids with an average value of $53-65 \%$ and $24-50 \%$, respectively (Özcan, 2007), which, together with the oxidative stability, represent similar characteristics to those presented by olive oil. Actually, tocopherols and phenolic compounds, such as phenolic acids, flavonoids and tannins (which have been reported as strong natural antioxidants), are considered as being the primary bioactive compounds in acorn fruits (Cantos et al., 2003; Lopes and BernardoGil, 2005; Rakić et al., 2006, 2007; Tejerina et al., 2011). These components have been associated with biological functions, such as anti-tumoral, anti-allergic, anti-platelet, anti-ischemic and antiinflammatory activities (Ostertag et al., 2011; Heleno et al., 2015), inclusively when evaluated under epidemiologic studies (Pandey and Rizvi, 2009). 
Some studies reporting the chemical characterization of nut shells have already been published, such as those presented by Shahidi et al. (2007) and Contini et al. (2008), who investigated the bioactive compounds in European hazelnuts and found that extracts of hazelnut shells exhibited higher antioxidant activity than its kernel. Different extracts of chestnut shells were also evaluated regarding the antioxidant activity, which was shown to be correlated with the high tannin contents (Barreira et al., 2008; Vázquez et al., 2008). Nevertheless, and as far as it could be concluded, there are no studies conducted on acorn pericarps alone.

Taking into account the potential of bioactive compounds in acorn components, this study aimed to quantify and compare different chemical parameters and bioactivity indicators in four Quercus species: Q. faginea (Portuguese oak), Q. ilex (evergreen oak), $Q$. nigra (red oak) and $Q$. suber (cork oak), evaluating whole fruits, kernels and pericarps (byproducts of industrial processing). Besides acorns per se, the byproducts potentially generated might represent sources of specific bioactive phytochemicals with different industrial applications.

\section{Materials and methods}

\subsection{Standards and reagents}

For the macronutrient analysis all analytical grade reagents were purchased from Panreac (Barcelona, Spain) and Merck (Darmstadt, Germany). Tocopherols ( $\alpha, \beta, \gamma$ and $\delta$ ) and tocotrienols ( $\alpha$, $\beta, \gamma$ and $\delta$ ) were purchased from Calbiochem (La Jolla, California, USA) and tocol (2-methyl-2-(4,8,12-trimethyl-tridecyl)chroman6-ol) was obtained from Matreya Inc. (Pennsylvania, USA). The mixture of methyl esters of fatty acids (FAME) standards Supelco37 were obtained from Supelco (Bellefonte, PA, USA). 1,1-diphenyl2-picrylhydrazyl $\left(\mathrm{DPPH}^{\bullet}\right)$ free radical, Folin-Ciocalteu's reagent, gallic acid, glycerol, TPTZ (2,4,6-tripyridyl-s-triazine) solution, petroleum ether, potassium hydroxide, anhydrous sodium sulfate, ferrous sulfate heptahydrate were purchased from Sigma-Aldrich (Steinheim, Germany). Ethanol reagent grade, sodium acetate, sodium carbonate decahydrate, sodium nitrite, aluminum chloride, acetone, $n$-hexane, methanol and sodium hydroxide were purchased from Merck (Darmstadt, Germany). HPLC-grade $n$-hexane and 1,4-dioxane were from Fluka (Madrid, Spain). HPLC grade $n$ hexane was from Merck (Darmstad, Germany). Purified water was obtained from a Milli-Q water purification system (Millipore, Bedford, MA, USA).

\subsection{Samples and samples preparation}

For the present work, four different acorn species ( $Q$. suber, $Q$. faginea, $Q$. nigra and $Q$. ilex) were selected due to the elevated representativeness among Mediterranean forest. Samples were collected in Trás-os-Montes region (Latitude: $41.538^{\circ}$, Longitude: $-6.911^{\circ}$ ). Whole fruits were haphazardly collected from ten trees per species in September, 2014. Freshly collected fruits (approximately $5 \mathrm{~kg}$ for each species) were cleaned and used to prepare three distinct sample groups for each component: whole fruits, kernels and pericarps (manually peeled off). All samples were frozen, lyophilized $\left(48 \mathrm{~h},-78^{\circ} \mathrm{C}, 0.015 \mathrm{mbar}\right.$ ) (Telstar Cryodos-80, Terrassa, Barcelona), reduced to powder in a mill (Grindomix GM 200, Retsch, Haan, Germany), homogenized and stored in plastic tubes at $4{ }^{\circ} \mathrm{C}$ until further analysis.

\subsection{Proximate analysis}

Macronutrients (moisture, ash, fat, protein and carbohydrates) were analyzed following the Association of Official Analytical Chemists methods (AOAC, 2012).
The moisture content was instrumentally determined using an infrared moisture analyzer (SMO 01, Scaltec Instruments, Heiligenstadt, Germany). The ash content was determined by incineration at $550 \pm 15^{\circ} \mathrm{C}$ approximately during $5 \mathrm{~h}$, until the sample was converted in a whitish ash. The crude fat was determined by extracting a known weight of powdered sample with petroleum ether, using a Soxhlet apparatus. The protein content $(N \times 6.25)$ was determined using the Kjeldahl procedure. Total carbohydrates were calculated as the difference between $100 \mathrm{~g}$ and the sum of the contents obtained for ash, crude fat and protein. Energy value was calculated according to the general Atwater factors (Atwater and Benedict, 1902): Energy $(\mathrm{kcal})=4 \times($ g protein $)+3.75 \times(\mathrm{g}$ carbohydrate $)+9 \times(\mathrm{g}$ fat $)$. The results are expressed as $\mathrm{g}$ per $100 \mathrm{~g}$ of dried mass.

\subsection{Fatty acids composition}

Fatty acids methyl esters (FAME) were prepared, in triplicate, according to ISO (129662:2011).

The analysis was carried out with a Shimadzu GC-2010 Plus gas chromatograph equipped with a split-splitless Shimadzu AOC-20i injector and a FID detector (Shimadzu, Tokyo, Japan). A CP-Sil 88 silica capillary column for FAME $(50 \mathrm{~m} \times 0.25 \mathrm{~mm}$ i.d, $0.20 \mu \mathrm{m}$ film thickness; Varian, Middelburg, Netherlands) was used. Helium was used as gas carrier $(40 \mathrm{~mL} / \mathrm{min})$ and separation was achieved with the following temperature program: $5 \mathrm{~min}$ at $120^{\circ} \mathrm{C}$, increase of $3^{\circ} \mathrm{C} /$ min from $120^{\circ} \mathrm{C}$ to $220^{\circ} \mathrm{C}$, maintaining $220^{\circ} \mathrm{C}$ for $10 \mathrm{~min}$. The temperature of the injector and detector was $250^{\circ} \mathrm{C}$ and $270^{\circ} \mathrm{C}$, respectively; a split ratio of 1:25 was used and the injection volume was $1 \mu \mathrm{L}$. FAME were identified by comparing the relative retention times with a standard mixture (FAME 37, Supelco, Bellefonte, PA, USA) and analyzed using the Shimadzu software GC Solution (v. 2.30, Shimadzu GC Solution, Shimadzu, Tokyo, Japan) based on the relative peak areas. The results were expressed in relative percentage of each fatty acid.

\subsection{Vitamin $E$}

For identification and quantification of individual compounds standard solutions of $\alpha-, \beta-, \gamma$ - and $\delta$-tocopherol and $\alpha-, \beta-, \gamma$ - and $\delta$-tocotrienol were prepared in $n$-hexane $(25,18.75,12.5,6.25,2.5$ and $1.25 \mathrm{mg} / \mathrm{mL}$ ). Each of these solutions contained $20 \mu \mathrm{L}$ of tocol (internal standard, $1 \mathrm{mg} / \mathrm{mL}$ ).

The lipid fraction for tocopherols quantification was obtained by Soxhlet extraction with petroleum ether $(2.5 \mathrm{~h})$. Analysis was carried out in an HPLC integrated system equipped with an AS-2057 automated injector, a PU-2089 pump, a MD-2018 multiwavelength diode array detector (DAD) and a FP-2020 fluorescence detector (Jasco, MD, USA), programmed for excitation at 290 and emission at $330 \mathrm{~nm}$ (Rodrigues et al., 2015). The chromatographic separation was achieved on a normal phase Supelcosil ${ }^{\mathrm{TM}}$ LC-SI $(3 \mu \mathrm{m}$; $75 \mathrm{~mm} \times 3.0 \mathrm{~mm}$; Supelco, Bellefonte, PA, USA). Chromatographic data were analyzed using JASCO-Chrom NAV Chromatography Software (Jasco, Japan). The compounds were identified based on the UV/vis spectra and respective retention time patterns. Quantification was based on the fluorescence signal, using the internal standard method. Final results were expressed in $\mathrm{mg} / 100 \mathrm{~g}$ of fat.

\subsection{Chlorophylls and carotenoids quantification}

The chlorophylls ( $a$ and $b$ ), $\beta$-carotene and lycopene were determined according to the methodology proposed by Nagata and Yamashita (1992), slightly modified by Vinha et al. (2014). Briefly, $\sim 0.5 \mathrm{~g}$ acorn samples were extracted with $10 \mathrm{~mL}$ of acetone/hexane $(4: 6, \mathrm{v} / \mathrm{v})$ and centrifuged at $5000 \mathrm{rpm}$, during $30 \mathrm{~min}$. Then, the absorbance of the supernatants was measured at 453 , 
505, 645, and $663 \mathrm{~nm}$ (BioTek Synergy HT microplate reader, GEN5, Winooski, Vermont, USA). The contents in chlorophylls and carotenoids were calculated according to the following equations: Chlorophyll $a(\mathrm{mg} / 100 \mathrm{~mL})=0.999 \mathrm{~A}_{663}-0.0989 \mathrm{~A}_{645}$; Chlorophyll $b(\mathrm{mg} / 100 \mathrm{~mL})=-0.328 \mathrm{~A}_{663}+1.77 \mathrm{~A}_{645} ; \beta$-carotene $(\mathrm{mg} / 100 \mathrm{~mL})=0.216 \mathrm{~A}_{663}-1.22 \mathrm{~A}_{645}-0.304 \mathrm{~A}_{505}+0.452 \mathrm{~A}_{453}$; Lycopene $\quad(\mathrm{mg} / 100 \mathrm{~mL})=-0.0458 \mathrm{~A}_{663}+0.204 \mathrm{~A}_{645}+0.372 \mathrm{~A}_{505}-$ $0.0806 \mathrm{~A}_{453}$, and further expressed in $\mathrm{mg} / 100 \mathrm{~g}$ of dried ample.

\subsection{Antioxidant activity}

\subsubsection{Preparation of hydro-alcoholic extracts}

The hydro-alcoholic extracts were obtained using $0.5 \mathrm{~g}$ of each powdered sample with $100 \mathrm{~mL}$ of ethanol:water $(1: 1, \mathrm{v} / \mathrm{v})$ at $40^{\circ} \mathrm{C}$ for $60 \mathrm{~min}$ (Mirac, Thermolyne, USA), according to Costa et al. (2014). Afterwards, extracts were filtered through Whatman no. 1 filter paper, and kept at $-25^{\circ} \mathrm{C}$ until being used for quantification of total phenolics and antioxidant activity assays.

\subsubsection{Total phenolics quantification}

The amount of total phenolics was determined according to Alves et al. (2010). Briefly, $500 \mu \mathrm{L}$ of each hydro-alcoholic diluted $(1: 10 \mathrm{v} / \mathrm{v})$ extract were mixed with $2.5 \mathrm{~mL}$ of the FolinCiocalteau reagent $(1: 10)$ and $2.5 \mathrm{~mL}$ of a sodium carbonate solution $(7.5 \% \mathrm{~m} / \mathrm{v})$. The mixture was first incubated at $45^{\circ} \mathrm{C}$, during $15 \mathrm{~min}$, followed by $30 \mathrm{~min}$ incubation at room temperature $\left(\sim 25^{\circ} \mathrm{C}\right)$. Absorbance readings were performed at $765 \mathrm{~nm}$ using a microplate reading Synergy HT (Bio Tek Instruments, Synergy HT GENS5, EUA). Total phenolic contents were calculated from a calibration curve prepared with gallic acid $(0-150 \mathrm{mg} / \mathrm{L} ; r=0.9986)$ and results were expressed as mg of gallic acid equivalents (GAE)/g of dried mass.

\subsubsection{DPPH radical-scavenging activity}

The anti-radical ability of the extracts was evaluated according to Brand-Williams et al. (1995) with minor modifications. The reaction mixture was prepared directly on a 96 well plate, consisting of a solution of different sample concentrations $(20 \mu \mathrm{L})$ and an ethanolic solution $(180 \mu \mathrm{L})$ containing DPPH radicals $\left(6 \times 10^{-5} \mathrm{~mol} / \mathrm{L}\right)$ in each well. The reduction of the DPPH radical was determined by measuring the absorption at $525 \mathrm{~nm}$, during $40 \mathrm{~min}$ until stabilization of the reaction. The radical scavenging activity (RSA) was calculated as a percentage of DPPH inhibition using the equation: \% $R S A=\left[\left(A_{D P P H}-A_{S}\right) / A_{D P P H}\right] \times 100$, where $A_{S}$ is the absorbance of the solution when the sample extract has been added at a particular level, and $A_{D P P H}$ is the absorbance of the DPPH solution at initial time.

\subsubsection{Ferric reducing antioxidant power (FRAP) assay}

The FRAP assay was carried out according to Benzie and Strain (1999) with minor modifications. This method is based on the reduction of a ferric 2,4,6-tripyridyl-s-triazine complex $\left(\mathrm{Fe}^{3+}-\mathrm{TPTZ}\right)$ to its ferrous form ( $\left.\mathrm{Fe}^{2+}-\mathrm{TPTZ}\right)$. An aliquot $(90 \mu \mathrm{L})$ of each extract (with appropriate dilution, if necessary) was added to $270 \mu \mathrm{L}$ of distilled water and $2.7 \mathrm{~mL}$ of the FRAP reagent (10 parts of $300 \mathrm{mM}$ sodium acetate buffer at $\mathrm{pH} 3.6,1$ part of $10 \mathrm{mM}$ TPTZ solution and 1 part of $20 \mathrm{mM} \mathrm{FeCl} 3 \cdot 6 \mathrm{H}_{2} \mathrm{O}$ solution). The reaction mixture was then incubated at $37^{\circ} \mathrm{C}$. The increase in the absorbance at $595 \mathrm{~nm}$ was measured after $30 \mathrm{~min}$. Solutions of known Fe(II) concentrations $\left(\mathrm{FeSO}_{4} \cdot 7 \mathrm{H}_{2} \mathrm{O}\right)$ were used for calibration. A calibration curve was prepared with ferrous sulfate (linearity range: $0-840 \mathrm{mg} / \mathrm{L}$, $r=0.9976$ ), and the results were expressed as ferrous sulfate equivalents/g of dried plant material.

\subsection{Statistical analysis}

All statistical tests were performed at a 5\% significance level using IBM SPSS Statistics for Windows, version 22.0. (IBM Corp., Armonk, NY, USA).

Data were expressed as mean \pm standard deviation, maintaining the significant numbers allowed by the magnitude of the standard deviation. An analysis of variance (ANOVA) with type III sums of squares was performed using the general linear model (GLM) procedure. The dependent variables were analyzed using 2-way ANOVA with the factors "acorn tissues" (AT) and "Quercus species" (QS). When a statistically significant interaction among factors was detected, these were evaluated simultaneously by the estimated marginal means plots for all levels of each factor. On the other hand, if no statistical significant interaction was found, the means were compared using Tukey's multiple comparison test, after a previous assessment of the equality of variances through the Levene's test.

Principal components analysis (PCA) was applied as a pattern recognition unsupervised classification method. The number of dimensions to keep for data analysis was assessed by the respective eigenvalues (which should be greater than one), by the Cronbach's alpha parameter (that must be positive) and also by the total percentage of variance (that should be as high as possible) explained by the number of components selected. The number of plotted dimensions was chosen to allow meaningful interpretations.

\section{Results and discussion}

In view of the potential use of acorns in industrial applications, it should be borne in mind that it is often difficult to ensure that the raw materials are obtained from the same Quercus species. Accordingly, it is mandatory to evaluate each considered acorn tissue independently of its phylogenetic origin, i.e., understand its potential regardless of the species in analysis. Likewise, it might also be useful to find which Quercus species has the highest suitability for a determined purpose, independently of the acorn part to be used. Accordingly, the average values presented for each species were calculated considering all the acorn parts; similarly, the average values for each acorn tissue comprise the results obtained for all species. Hence, the standard deviations result from samples prepared from different fruit parts or species and should not be regarded as a measure of accuracy of the applied methodologies. The interaction among factors (AT $\times \mathrm{QS})$ was also evaluated. As indicated in the Materials and methods section, when a significant interaction was found $(p<0.050)$, the results obtained from the multiple comparisons could be indicated. Therefore, the influence of each factor was assessed by interpreting the estimated marginal means (EMM) plots, since the interaction among factors was always significant.

\subsection{Macronutrients analysis}

In fresh mass (fm) basis (Table 1), the acorn kernel presented higher water content $(46 \pm 9 \mathrm{~g} / 100 \mathrm{gfm})$ than the whole fruit $(40 \pm 6 \mathrm{~g} / 100 \mathrm{~g} \mathrm{fm})$ and the pericarp $(27 \pm 5 \mathrm{~g} / 100 \mathrm{~g} \mathrm{fm})$, independently of the species. Likewise, the acorn parts from $Q$. suber had the highest water contents $(46 \pm 8 \mathrm{~g} / 100 \mathrm{~g} \mathrm{fm})$, whilst those from Q. ilex showed the lowest contents $(30 \pm 3 \mathrm{~g} / 100 \mathrm{~g} \mathrm{fm})$. Considering the composition in dried mass $(\mathrm{dm})$ basis, carbohydrates were the major component, reaching maximum values in the pericarps $(92 \pm 3 \mathrm{~g} / 100 \mathrm{~g} \mathrm{dm})$ and indistinguishable values in the kernels and whole fruits $(87 \pm 3 \mathrm{~g} / 100 \mathrm{gdm})$. Nevertheless, it should be reminded that pericarps are expected to have high percentages of lignin; thereby, the carbohydrates percentage might have been overestimated. In terms of species comparison, all the species pre- 
Table 1

Macronutrients profile and energy value of Quercus spp. components. Results are presented as mean \pm standard deviation.

\begin{tabular}{|c|c|c|c|c|c|c|c|}
\hline & & Water $(\mathrm{g} / 100 \mathrm{~g} \mathrm{fm})$ & Fat $(\mathrm{g} / 100 \mathrm{~g} \mathrm{dm})$ & Protein (g/100 g dm) & Ash (g/100 g dm) & Carbohydrates (g/100 g dm) & Energy (kcal/100 g dm) \\
\hline \multirow[t]{4}{*}{ AT } & Kernel & $46 \pm 9$ & $6 \pm 3$ & $6 \pm 2$ & $1.7 \pm 0.5$ & $87 \pm 3$ & $399 \pm 21$ \\
\hline & Whole fruit & $40 \pm 6$ & $5 \pm 3$ & $7 \pm 2$ & $1.9 \pm 0.5$ & $87 \pm 3$ & $393 \pm 18$ \\
\hline & Pericarp & $27 \pm 5$ & $0.8 \pm 0.2$ & $5 \pm 2$ & $1.5 \pm 0.5$ & $92 \pm 3$ & $375 \pm 2$ \\
\hline & $p$-value $^{1}(\mathrm{n}=36)$ & $<0.001$ & $<0.001$ & 0.010 & 0.003 & $<0.001$ & $<0.001$ \\
\hline \multirow[t]{5}{*}{ QS } & Q. faginea & $35 \pm 10$ & $2 \pm 1$ & $6 \pm 1$ & $2.0 \pm 0.2$ & $89 \pm 1$ & $381 \pm 7$ \\
\hline & Q. ilex & $30 \pm 3$ & $8 \pm 4$ & $4 \pm 1$ & $1.2 \pm 0.2$ & $87 \pm 6$ & $412 \pm 26$ \\
\hline & Q. nigra & $39 \pm 12$ & $2 \pm 1$ & $5 \pm 1$ & $1.2 \pm 0.3$ & $92 \pm 2$ & $381 \pm 3$ \\
\hline & Q. suber & $46 \pm 8$ & $3 \pm 1$ & $9 \pm 1$ & $2.5 \pm 0.4$ & $86 \pm 2$ & $382 \pm 6$ \\
\hline & $p$-value ${ }^{2}(\mathrm{n}=27)$ & $<0.001$ & $<0.001$ & $<0.001$ & $<0.001$ & $<0.001$ & $<0.001$ \\
\hline $\mathrm{AT} \times \mathrm{QS}$ & $p$-value ${ }^{3}(\mathrm{n}=108)$ & $<0.001$ & $<0.001$ & $<0.001$ & $<0.001$ & $<0.001$ & $<0.001$ \\
\hline
\end{tabular}

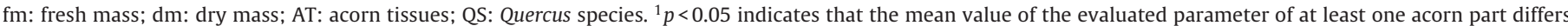

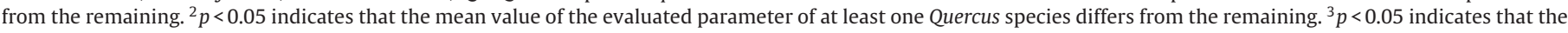
interaction among factors is significant (in this case, the multiple comparison tests could not be performed).

sented similar values ( $86-89 \mathrm{~g} / 100 \mathrm{~g} \mathrm{dm}$ ), except for $Q$. nigra, which had the highest carbohydrates contents $(92 \pm 2 \mathrm{~g} / 100 \mathrm{~g} \mathrm{dm})$. Protein was the second component in all cases except $Q$. ilex, in which the second most abundant component was fat $(8 \pm 4 \mathrm{~g} / 100 \mathrm{~g} \mathrm{dm})$. On the other hand, proteins reached maximal contents in $Q$. suber $(9 \pm 1 \mathrm{~g} / 100 \mathrm{~g} \mathrm{dm})$, while the acorn parts had lower differences (5-7 g/100 g dm) among each other. In general, the obtained values were higher than the reported in acorns obtained from $Q$. robur (pedunculate oak) and Q. petraea (Irish oak) (Deforce et al., 2009) and similar to the ones reported in Spanish acorns produced by $Q$. rotundifolia (holm oak) $(4.8 \mathrm{~g} / 100 \mathrm{~g} \mathrm{dm}$ ) and $Q$. suber $(6.3 \mathrm{~g} / 100 \mathrm{~g} \mathrm{dm})$ (Aguilera et al., 2002). Besides the fat content highlighted for $Q$. ilex, the remaining species had similar values $(2-3 \mathrm{~g} / 100 \mathrm{gdm})$, while the pericarps showed minimal contents (concerning the comparison among acorn tissues). In contrast, the kernels, whole fruits and pericarps presented similar values in mineralized material $(1.5-1.9 \mathrm{~g} / 100 \mathrm{~g} \mathrm{dm})$, which, in turn, presented significant differences among Quercus species $(1.2 \pm 0.2 \mathrm{~g} / 100 \mathrm{~g} \mathrm{dm}$ in $Q$. ilex and $1.2 \pm 0.3$ in $Q$. nigra, $2.0 \pm 0.2 \mathrm{~g} / 100 \mathrm{~g} \mathrm{dm}$ in $Q$. faginea and $2.5 \pm 0.4 \mathrm{~g} / 100 \mathrm{~g} \mathrm{dm}$ in $Q$. suber). Finally, the kernels had the highest energetic value $(399 \pm 21 \mathrm{kcal} / 100 \mathrm{~g} \mathrm{dm})$, followed by the whole fruits $(393 \pm 18 \mathrm{kcal} / 100 \mathrm{gdm})$ and the pericarps $(375 \pm 2 \mathrm{kcal} / 100 \mathrm{~g} \mathrm{dm})$. Q. ilex, perhaps in result of its higher fat content, presented the highest energy value $(412 \pm 26 \mathrm{kcal} / 100 \mathrm{~g} \mathrm{dm})$, while the remaining species presented nearly the same value (381-382 kcal/100 g dm).

\subsection{Fatty acids $(F A)$}

The most representative FA are presented in Table 2 . In addition to the tabled molecules, C4:0, C8:0, C10:0, C12:0, C14:0, C15:0, C17:0, C20:1, C21:0 and C22:2 were also detected, but in percentages below $0.5 \%$. Oleic acid (C18:1n9c) was the main fatty acid in all cases, varying from $49 \pm 9 \%$ in the pericarps to $58 \pm 7 \%$ in the whole fruits, and from $48 \pm 2 \%$ in Q. nigra to $64 \pm 7 \%$ in Q. ilex. Linoleic acid (C18:2n6c) was also present in relevant percentages, showing some statistically significant differences among species $(Q$. faginea: $20 \pm 2 \%$, Q. ilex: $14 \pm 2 \%$; Q. nigra: $26 \pm 6 \%$; Q. suber: $21 \pm 3 \%$ ) and acorn parts (kernels: $22 \pm 7 \%$, whole fruits $21 \pm 5 \%$, pericarps: $18 \pm 2 \%$ ). Oleic and linoleic acids were previously reported as the predominant fatty acids in Quercus species (Cantos et al., 2003; Petrović et al., 2004; Gea-Izquierdo et al., 2006; Tejerina et al., 2011), emphasizing the interest of these natural matrices (especially in the case of $Q$. ilex, considering its fat content), considering the health-promoting effects attributed to unsaturated fatty acids (Lands, 2014). Among the saturated fatty acids (SFA), palmitic acid (C16:0) was quantified in the highest percentages, once again with significant differences among species ( $Q$. faginea: $18 \pm 4 \%$, Q. ilex: $14 \pm 1 \%$; Q. nigra: $17 \pm 1 \%$; Q. suber: $14 \pm 1 \%$ ) and acorn tissues (kernels: $15 \pm 2 \%$, whole fruits $14 \pm 1 \%$, pericarps: $17 \%$ ). In general, acorns FA profiles were similar to those typically detected in mastic, sunflower, peanut, cotton, olive and avocado oils (Charef et al., 2008).

\subsection{Vitamin E composition}

Five different isoforms of vitamin E were detected, with $\alpha$ tocopherol and $\gamma$-tocopherol as the predominant compounds (Table 3). The vitamin E profiles varied greatly among Quercus species and different botanical parts, as indicated by the high standard deviation presented below. Among the identified vitamers, $\gamma$-tocopherol was the only one lacking statistically significant differences $(p=0.094)$, despite the tendency to higher contents shown by $Q$. nigra $(8 \pm 6 \mathrm{mg} / 100 \mathrm{~g}$ oil). $Q$. faginea, on the other hand, showed the maximum average contents in $\alpha$-tocopherol ( $7 \pm 7 \mathrm{mg} / 100 \mathrm{~g}$ oil). $\alpha$-Tocopherol $(6 \pm 6 \mathrm{mg} / 100 \mathrm{~g}$ oil) was maximized in whole fruits, while $\gamma$-tocopherol $(11 \pm 4 \mathrm{mg} / 100 \mathrm{~g}$ oil $)$ reached the highest levels in the kernels of all species. $\beta$-tocopherol, $\delta$-tocopherol and $\alpha$-tocotrienol were also quantified, but in minor levels $(\leq 0.3 \mathrm{mg} / 100 \mathrm{~g}$ oil). Regarding total vitamin $\mathrm{E}$, the results herein indicate lower quantities than those reported previously in related Quercus species (Gea-Izquierdo et al., 2006; Tejerina et al., 2011), where a different extraction technique was followed. Considering that tocopherols are strong lipophilic antioxidants (Barreira et al., 2009b) the low detected quantities might be interpreted as a reliable indicator of the oxidative stability of the lipid fraction of acorns.

\subsection{Carotenoids, chlorophylls and antioxidant activity}

As a preliminary indicator of the potential bioactivity of the studied acorns, the antioxidant activity was evaluated by measuring the scavenging activity against DPPH radicals and the ferric reducing power (Table 4 ).

Interestingly, the kernels tended to have the highest activity in both assays, which is a surprising result as the corresponding parts of similar fruits present less activity than the pericarps (Barreira et al., 2008). When comparing the Quercus species (using extracts at $1 \mathrm{mg} / \mathrm{mL}$ ), the results were similar for all cases (presenting approximately $70 \%$ of inhibition), except for $Q$. ilex, which tended to show lower scavenging activity ( $42 \pm 6 \%$ of inhibition). Concerning the ferric reducing power, $Q$. faginea stood out as the species with the highest power $(827 \pm 302 \mu \mathrm{mol} F S E / g$ of $\mathrm{dm})$, whilst $Q$. ilex showed the least strong activity in this assay $(638 \pm 297 \mu \mathrm{mol} \mathrm{FSE} / \mathrm{g}$ of $\mathrm{dm}$ ). In either case, the measured activities are slightly higher than those described in acorns (Custódio et al., 2015). Besides the antioxidant assays, the contents in chlorophyll a, chlorophyll $b$, lycopene, $\beta$-carotene and phenolics were also evaluated. As 
Table 2

Fatty acids profiles of Quercus spp. components. Results are presented as mean \pm standard deviation.

\begin{tabular}{|c|c|c|c|c|c|c|c|c|c|c|c|c|c|}
\hline & & C16:0 (\%) & C16:1 (\%) & C18:0 (\%) & C18:1n9c (\%) & $\mathrm{C} 18: 2 \mathrm{n} 6 \mathrm{c}(\%)$ & C20:0 (\%) & C18:3n3 (\%) & C22:1n9 (\%) & C24:0 (\%) & SFA (\%) & MUFA (\%) & PUFA (\%) \\
\hline \multirow[t]{4}{*}{ AT } & Kernel & $15 \pm 2$ & $0.3 \pm 0.2$ & $1.2 \pm 0.5$ & $57 \pm 8$ & $22 \pm 7$ & $0.4 \pm 0.1$ & $2 \pm 1$ & $0.2 \pm 0.1$ & $0.1 \pm 0.1$ & $16 \pm 2$ & $61 \pm 8$ & $23 \pm 7$ \\
\hline & Whole fruit & $14 \pm 1$ & $0.8 \pm 0.8$ & $1.2 \pm 0.5$ & $58 \pm 7$ & $21 \pm 5$ & $0.4 \pm 0.1$ & $3 \pm 2$ & $0.2 \pm 0.1$ & $0.1 \pm 0.1$ & $16 \pm 2$ & $62 \pm 7$ & $22 \pm 5$ \\
\hline & Pericarp & $17 \pm 4$ & $0.4 \pm 0.3$ & $3.5 \pm 0.3$ & $49 \pm 9$ & $18 \pm 2$ & $0.4 \pm 0.2$ & $7 \pm 4$ & $0.7 \pm 0.4$ & $2 \pm 2$ & $25 \pm 3$ & $57 \pm 4$ & $19 \pm 2$ \\
\hline & $p$-value ${ }^{1}(\mathrm{n}=36)$ & $<0.001$ & $<0.001$ & $<0.001$ & $<0.001$ & 0.001 & 0.132 & $<0.001$ & $<0.001$ & $<0.001$ & $<0.001$ & 0.001 & 0.003 \\
\hline \multirow[t]{5}{*}{ QS } & Q. faginea & $18 \pm 4$ & $0.3 \pm 0.1$ & $2 \pm 1$ & $51 \pm 12$ & $20 \pm 2$ & $0.5 \pm 0.1$ & $5 \pm 5$ & $0.6 \pm 0.5$ & $0.4 \pm 0.4$ & $22 \pm 6$ & $57 \pm 5$ & $21 \pm 2$ \\
\hline & Q. ilex & $14 \pm 1$ & $0.3 \pm 0.2$ & $1 \pm 1$ & $64 \pm 7$ & $14 \pm 2$ & $0.4 \pm 0.1$ & $2 \pm 1$ & $0.3 \pm 0.2$ & $0.3 \pm 0.3$ & $16 \pm 4$ & $69 \pm 6$ & $15 \pm 2$ \\
\hline & Q. nigra & $17 \pm 1$ & $0.5 \pm 0.2$ & $2 \pm 1$ & $48 \pm 2$ & $26 \pm 6$ & $0.5 \pm 0.1$ & $4 \pm 2$ & $0.5 \pm 0.3$ & $0.1 \pm 0.1$ & $20 \pm 3$ & $53 \pm 3$ & $27 \pm 6$ \\
\hline & Q. suber & $14 \pm 1$ & $1.0 \pm 1.0$ & $2 \pm 1$ & $55 \pm 2$ & $21 \pm 3$ & $0.1 \pm 0.1$ & $4 \pm 1$ & $0.1 \pm 0.1$ & $2 \pm 2$ & $18 \pm 3$ & $60 \pm 2$ & $21 \pm 3$ \\
\hline & $p$-value $^{2}(n=27)$ & $<0.001$ & $<0.001$ & $<0.001$ & $<0.001$ & $<0.001$ & $<0.001$ & 0.001 & $<0.001$ & $<0.001$ & $<0.001$ & $<0.001$ & $<0.001$ \\
\hline $\mathrm{AT} \times \mathrm{QS}$ & $p$-value ${ }^{3}(\mathrm{n}=108)$ & $<0.001$ & $<0.001$ & $<0.001$ & $<0.001$ & $<0.001$ & $<0.001$ & $<0.001$ & $<0.001$ & $<0.001$ & $<0.001$ & $<0.001$ & $<0.001$ \\
\hline
\end{tabular}

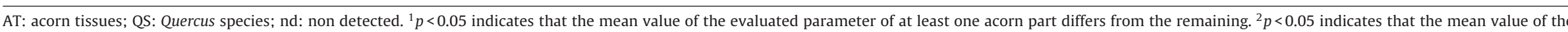

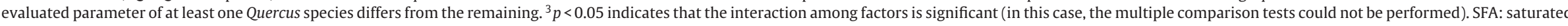
fatty acids; MUFA: monounsaturated fatty acids; PUFA: polyunsaturated fatty acids.

Table 3

Vitamin E composition of Quercus spp. components. Results are presented as mean \pm standard deviation.

\begin{tabular}{|c|c|c|c|c|c|c|c|}
\hline & & $\alpha$-Tocopherol (mg/100g oil) & $\beta$-Tocopherol (mg/100g oil) & $\gamma$-Tocopherol (mg/100g oil) & $\delta$-Tocopherol (mg/100 g oil) & $\alpha$-Tocotrienol (mg/100 g oil) & Vitamin E (mg/100 g oil) \\
\hline \multirow[t]{4}{*}{ AT } & Kernel & $2 \pm 1$ & $0.05 \pm 0.02$ & $11 \pm 4$ & $0.3 \pm 0.1$ & $0.03 \pm 0.01$ & $13 \pm 5$ \\
\hline & Whole fruit & $6 \pm 6$ & $0.3 \pm 0.3$ & $4 \pm 2$ & $0.3 \pm 0.2$ & $0.05 \pm 0.04$ & $11 \pm 8$ \\
\hline & Pericarp & $2 \pm 1$ & $0.07 \pm 0.06$ & $2 \pm 1$ & $0.1 \pm 0.1$ & $0.02 \pm 0.01$ & $4 \pm 2$ \\
\hline & $p$-value $^{1}(\mathrm{n}=36)$ & $<0.001$ & $<0.001$ & 0.010 & 0.003 & $<0.001$ & $<0.001$ \\
\hline \multirow[t]{5}{*}{ QS } & Q. faginea & $7 \pm 7$ & $0.3 \pm 0.3$ & $5 \pm 1$ & $0.3 \pm 0.2$ & $0.06 \pm 0.04$ & $13 \pm 9$ \\
\hline & Q. ilex & $0.7 \pm 0.1$ & $0.026 \pm 0.004$ & $5 \pm 3$ & $0.2 \pm 0.1$ & $0.03 \pm 0.01$ & $6 \pm 3$ \\
\hline & Q. nigra & $2 \pm 1$ & $0.12 \pm 0.05$ & $8 \pm 6$ & $0.2 \pm 0.1$ & $0.01 \pm 0.01$ & $10 \pm 6$ \\
\hline & Q. suber & $2 \pm 1$ & $0.07 \pm 0.03$ & $5 \pm 5$ & $0.2 \pm 0.1$ & $0.03 \pm 0.01$ & $7 \pm 4$ \\
\hline & $p$-value $^{2}(\mathrm{n}=27)$ & $<0.001$ & $<0.001$ & 0.094 & 0.027 & $<0.001$ & 0.001 \\
\hline $\mathrm{AT} \times \mathrm{QS}$ & $p$-value $^{3}(\mathrm{n}=108)$ & $<0.001$ & $<0.001$ & $<0.001$ & $<0.001$ & $<0.001$ & $<0.001$ \\
\hline
\end{tabular}

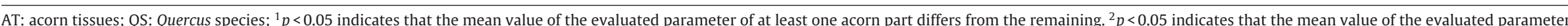
of at least one Quercus species differs from the remaining. ${ }^{3} p<0.05$ indicates that the interaction among factors is significant (in this case, the multiple comparison tests could not be performed). 


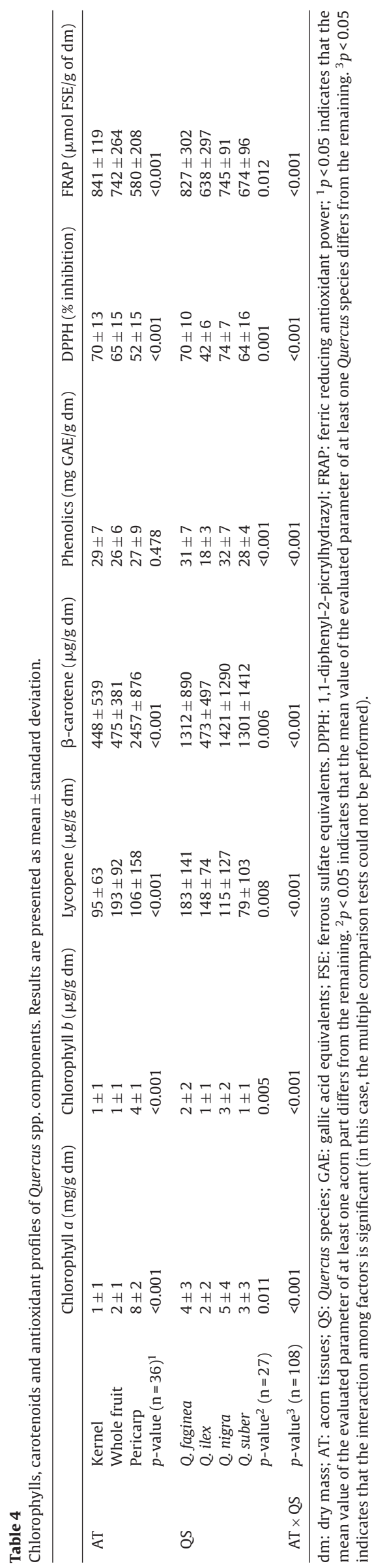

it would be expectable, the pericarps showed the highest content in chlorophylls, which did not vary significantly among the Quercus species. On the other hand, the lycopene content showed significant changes among species, with $Q$. suber giving the least quantity $(79 \pm 103 \mu \mathrm{g} / \mathrm{g} \mathrm{dm})$, in contrast with $Q$. faginea, which gave the top quantity $(183 \pm 141 \mu \mathrm{g} / \mathrm{g} \mathrm{dm})$ in this carotenoid. Among the acorn tissues, the whole fruits $(193 \pm 92 \mu \mathrm{g} / \mathrm{g} \mathrm{dm})$ showed the highest contents in lycopene. The results were different for $\beta$-carotene, which was present in the pericarps in contents nearly fivefold higher than in the remaining acorn parts. Among Quercus species, Q. ilex presented the lowest $\beta$-carotene contents $(473 \pm 497 \mu \mathrm{g} / \mathrm{g} \mathrm{dm})$, whilst the remaining species presented similar values (1301-1421 $\mu \mathrm{g} / \mathrm{g} \mathrm{dm}$ ). Finally, the acorn tissues did not show statistically significant differences $(p=0.478)$ for the phenolic compounds, while $Q$. ilex gave lower contents $(18 \pm 3 \mathrm{mg} \mathrm{GAE} / \mathrm{g}$ $\mathrm{dm}$ ) than the remaining species (28-32 $\mathrm{mg} \mathrm{GAE} / \mathrm{g} \mathrm{dm}$ ). Considering previous findings (Cantos et al., 2003; Rakić et al., 2006; Tejerina et al., 2011), these phenolic compounds should include phenolic acids (gallic acid and its derivatives and ellagic acid), flavonoids and tannins. The high antioxidant activity of these compounds is a reasonable explanation for the highest correlations (evaluated by the Spearman rho), which were verified in this work among DPPH radicals scavenging inhibition (0.653) and among FRAP (0.596) and phenolic compounds contents.

\subsection{Principal components analysis (PCA)}

In the former sections, the differences among the acorn tissues and the Quercus species were compared analyzing each parameter individually. In most cases, the detected differences were statistically significant, but the parameters with the highest differences for each acorn part or Quercus are yet to be identified. Accordingly, the results were evaluated considering data for all parameters (nutritional, chemical and antioxidant activity) simultaneously, by applying principal components analysis (PCA).

The correlations among the first three PC and each of the 41 included parameters are indicated in Table 5, showing which parameters contributed mostly to define the obtained PCs. The parameters more highly correlated with PC1 were carbohydrates, C12:0, C14:0, C15:0, C17:0, C18:0, C20:1, C18:3n3, C22:1n9, SFA, chlorophyll a, chlorophyll $b$ and $\beta$-carotene. Analyzing the 3D plot (Fig. 1A), it is obvious that markers corresponding to the pericarps were the only ones scoring positively in PC1, indicating that these components present particularly high levels of all parameters (except C20:1) with the highest correlation with PC1. The higher levels of chlorophyll a, chlorophyll $b$ and $\beta$-carotene could have been anticipated, considering the color of the pericarps (brownishgreen) and the kernels (white). Likewise, the higher abundance of SFA is probably related with the fact that pericarps are more exposed to environmental stressors, thereby presenting fatty acids less prone to oxidation. Concerning the distribution of markers according to PC2 and PC3 it was not possible to obtain a clear separation among kernels and whole fruits, thereby indicating that the parameters more highly correlated with PC2 (moisture, fat, energy, C18:1n9c, C18:2n6c, MUFA, PUFA, phenolics and DPPH scavenging activity) and PC3 (protein and ash) scored similarly for those acorn parts.

On the other hand, the markers corresponding to each Quercus species were not clustered individually by PC1 (Fig. 1B), which indicates the similarity among species for all the parameters more highly correlated with PC1. According to PC2, Q. ilex was significantly different from the remaining species, mostly due to its higher levels in fat, energy, C18:1n9c and MUFA, and the lower (negative correlations) levels in all the remaining parameters highlighted as having the highest correlations with PC2. Q. faginea and Q. suber scored positively on PC3, in opposition to Q. ilex and Q. nigra, prob- 

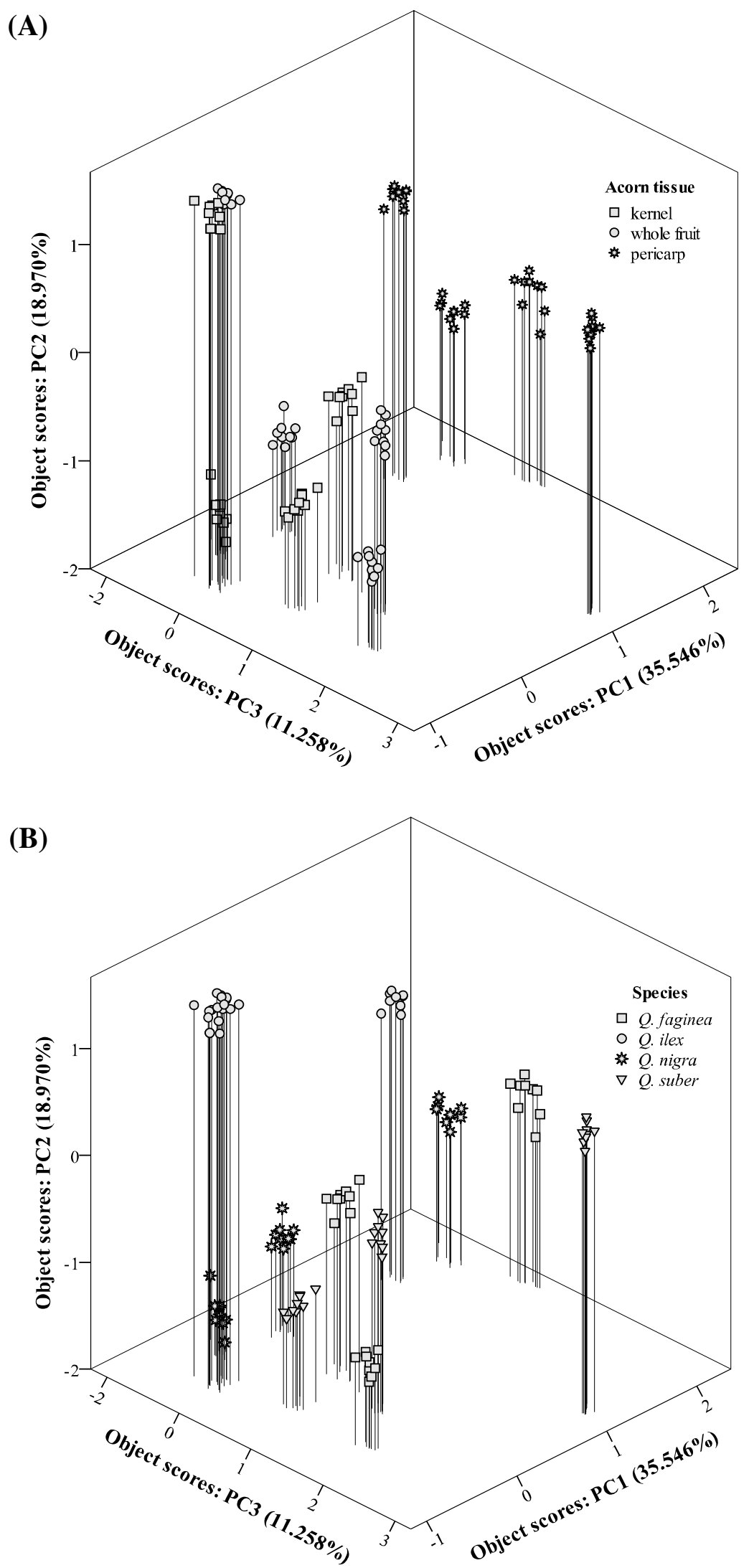

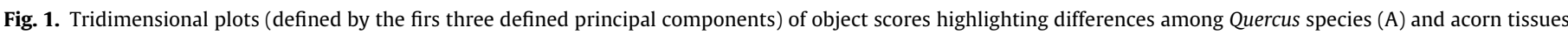

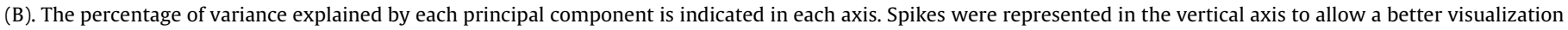
of the tridimensional projection of objects. 
Table 5

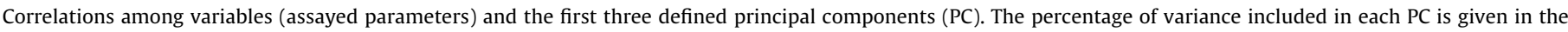
bottom line of the table. Numbers highlighted in bold represent the highest absolute correlations among variables and principal components.

\begin{tabular}{|c|c|c|c|c|c|c|c|}
\hline Variable & PC1 & PC2 & PC3 & Variable (cont.) & PC1 & PC2 & PC3 \\
\hline Moisture & -0.646 & -0.602 & 0.235 & $\mathrm{C} 22: 2$ & -0.670 & -0.542 & -0.100 \\
\hline Fat & -0.671 & 0.631 & -0.225 & $\mathrm{C} 24: 0$ & 0.525 & 0.292 & 0.576 \\
\hline Protein & -0.281 & -0.293 & 0.712 & SFA & 0.950 & -0.191 & 0.067 \\
\hline Ash & -0.319 & -0.226 & 0.677 & MUFA & -0.538 & 0.768 & 0.049 \\
\hline Carbohydrates & 0.731 & -0.306 & -0.279 & PUFA & -0.189 & -0.865 & -0.130 \\
\hline Energy & -0.645 & 0.630 & -0.291 & $\alpha$-tocopherol & -0.206 & -0.474 & 0.461 \\
\hline $\mathrm{C} 8: 0$ & -0.308 & -0.519 & -0.267 & $\alpha$-tocotrienol & -0.602 & 0.028 & 0.471 \\
\hline C10:0 & 0.220 & -0.489 & -0.387 & $\beta$-tocopherol & -0.129 & -0.439 & 0.318 \\
\hline $\mathrm{C} 12: 0$ & 0.819 & -0.068 & -0.171 & $\gamma$-tocopherol & -0.540 & -0.354 & -0.348 \\
\hline C14:0 & 0.834 & 0.157 & 0.351 & $\delta$-tocopherol & -0.543 & -0.349 & 0.042 \\
\hline $\mathrm{C} 15: 0$ & 0.840 & 0.207 & 0.358 & Tocopherols & -0.611 & -0.542 & 0.115 \\
\hline C16:0 & 0.693 & -0.392 & -0.313 & Chlorophyll $a$ & 0.919 & 0.127 & 0.109 \\
\hline C16:1 & 0.059 & -0.202 & -0.097 & Chlorophyll $b$ & 0.921 & 0.161 & -0.073 \\
\hline $\mathrm{C} 17: 0$ & 0.774 & -0.037 & -0.314 & Lycopene & -0.022 & 0.179 & -0.235 \\
\hline C18:0 & 0.910 & -0.158 & 0.184 & $\beta$-carotene & 0.843 & 0.035 & 0.330 \\
\hline C18:1n9c & -0.648 & 0.607 & 0.152 & Phenolics & 0.058 & -0.611 & 0.211 \\
\hline C18:2n6c & -0.187 & -0.862 & -0.127 & DPPH & -0.243 & -0.850 & -0.025 \\
\hline C20:0 & 0.425 & -0.226 & -0.605 & FRAP & -0.459 & -0.223 & 0.171 \\
\hline C18:3n3 & 0.757 & -0.283 & 0.034 & Eigenvalue & 15.350 & 7.967 & 4.728 \\
\hline C20:1 & -0.700 & -0.086 & -0.577 & Proportion of total variance (\%) & 36.546 & 18.970 & 11.258 \\
\hline $\mathrm{C} 21: 0$ & -0.597 & -0.116 & -0.478 & & & & \\
\hline $\mathrm{C} 22: 1 \mathrm{n} 9$ & 0.799 & -0.062 & -0.398 & & & & \\
\hline
\end{tabular}

DPPH: 1,1-diphenyl-2-picrylhydrazyl; FRAP: ferric reducing antioxidant power.

ably due to higher contents of protein and ash (the parameters more correlated with PC3) in Q. faginea and Q. suber.

\section{Conclusions}

Overall, the Quercus species gave significantly different results in the analyzed parameters (except for the $\gamma$-tocopherol). Likewise, the difference among the studied acorn tissues were also significant in most cases, except for C20:0 and phenolics content. The kernels emerged as the main source of oil, energy, C18:2n6c, $\gamma$ tocopherol and total tocopherols, while the whole fruits presented the highest levels of protein, $\alpha$-tocopherol and lycopene. These two components showed also similar values in C18:1n9c, MUFA and PUFA; the pericarps, on the other hand stood out for the high carbohydrates and $\beta$-carotene contents. From the comparison among species, $Q$. faginea gave the highest $\alpha$-tocopherol, total tocopherols and lycopene contents; $Q$. ilex emerged as a particularly interesting source of oil, energy, C18:1n9c and MUFA; the components from $Q$. nigra stood out for the contents in carbohydrates, C18:2n6, MUFA and $\beta$-carotene; finally, $Q$. suber showed the highest protein levels. The best antioxidant effectiveness was obtained in the kernels extracts and in the components of $Q$. nigra (for DPPH scavenging activity) and Q. faginea (for FRAP assay). From the industrial application standpoint, these results might be useful for designing novel food and pharmaceutical products. Considering sustainability principles, the results could be useful in providing added-value to byproducts from industrial processing of acorns or the generated agricultural wastes.

\section{Acknowledgements}

The authors are grateful for the financial support to REQUIMTE/LAQV (UID/QUI/50006/2013 POCI/01/0145/FEDER/007265) and CIMO (UID/AGR/00690/2013) from FCT/MEC through national funds and co-financed by FEDER, under the Partnership Agreement PT2020. J.C.M. Barreira thanks FCT, POPH-QREN and FSE for his grant (SFRH/BPD/72802/2010).

\section{References}

Aguilera, J.F., Nieto, R., Rivera, M., Garcia, M.A., 2002. Amino acid availability and energy value of acorn in the Iberian pig. Livest. Prod. Sci. 77, 227-239.

Alves, R.C., Costa, A.S.G., Jerez, M., Casal, S., Sineiro, J., Núñez, M.J., Oliveira, M.B.P.P., 2010. Antiradical activity, phenolics profile and hydroxymethylfurfural in expresso coffee: influence of technological factors. J. Agric. Food Chem. 58 $12221-12229$.

Amaral, J.S., Alves, M.R., Seabra, R.M., Oliveira, M.B.P.P., 2005. Vitamin E composition of walnuts (Juglans regia L.): a 3-year comparative study of different cultivars. J. Agric. Food Chem. 53, 5467-5472.

Amaral, J.S., Casal, S., Alves, M.R., Seabra, R.M., Oliveira, M.B.P.P., 2006. Tocopherol and tocotrienol content of hazelnut cultivars grown in Portugal. J. Agric. Food Chem. 54, 1329-1336.

AOAC, 2012. In Official methods of analysis of AOAC International, ed. W. Horwitz, Gaithersburg, USA, 19th ed.

Atwater, W.O., Benedict, F.G., 1902. Experiments on the Metabolism of Matter and Energy in the Human Body, 1898-1900. US Office of Experiment Stations Bulletin No. 109. Government Printing Office, Washington DC.

Baiano, A., 2014. Recovery of biomolecules from food wastes-a review. Molecules 19, 14821-14842.

Barreira, J.C.M., Ferreira, I.C.F.R., Oliveira, M.B.P.P., Pereira, J.A., 2008. Antioxidant activities of the extracts from chestnut flower, leaf, skins and fruit. Food Chem. 107, 1106-1113.

Barreira, J.C.M., Casal, S., Ferreira, I.C.F.R., Oliveira, M.B.P.P., Pereira, J.A., 2009a Nutritional: fatty acid and triacylglycerol profiles of Castanea sativa Mill. cultivars: a compositional and chemometric approach. J. Agric. Food Chem. 57, 2836-2842

Barreira, J.C.M., Alves, R.C., Casal, S., Ferreira, I.C.F.R., Oliveira, M.B.P.P., Pereira, J.A., 2009b. Vitamin E profile as a reliable authenticity discrimination factor between chestnut (Castanea sativa Mill.) cultivars. J. Agric. Food Chem. 57, 5524-5528.

Barreira, J.C.M., Casal, S., Ferreira, I.C.F.R., Peres, A.M., Pereira, J.A., Oliveira, M.B.P.P., 2012. Chemical characterization of chestnut cultivars from three consecutive years: chemometrics and contribution for authentication. Food Chem. Toxicol. 50, 2311-2317

Benzie, I.F.F., Strain, J.J., 1999. Methods in enzymology. In: Lester, P. (Ed.), Methods in Enzymology, vol. 299. Academic Press, pp. 15-27.

Brand-Williams, W., Cuvelier, M.E., Berset, C., 1995. Use of a free-radical method to evaluate antioxidant activity. LWT Food Sci. Technol. 28, 25-30.

Brizi, C., Santulli, C., Micucci, M., Budriesi, R., Chiarini, A., Aldinucci, C., Frosini, M., 2016. Neuroprotective effects of Castanea sativa Mill. bark extract in human neuroblastoma cells subjected to oxidative stress. J. Cell. Biochem. 117, 510-520.

Cantos, E., Espín, J.C., López-Bote, C., de La Hoz, L., Ordoñez, J.A., Tomás-Barberán, F.A., 2003. Phenolic compounds and fatty acids from acorns (Quercus spp.): the main dietary constituent of free-ranged Iberian pigs. J. Agric. Food Chem. 51, 6248-6255.

Charef, M., Mohamed, Y., Saidi, M., Stocker, P., 2008. Determination of the fatty acid composition of acorn (Quercus), Pistacia lentiscus seeds growing in Algeria. J. Am. Oil Chem. Soc. 85, 921-924. 
Contini, M., Baccelloni, S., Massantini, R., Anelli, G., 2008. Extraction of natural antioxidants from hazelnuts (Corylus avellana L.) shell and skin wastes by long maceration at room temperature. Food Chem. 110, 659-669.

Costa, A.S.G., Alves, R.C. Vinha, A.F. Barreira, S.V.P., Nunes, M.A., Cunha, L.M. Oliveira, M.B.P.P., 2014. Optimization of antioxidants extraction from coffee silverskin, a roasting by-product, having in view a sustainable process. Ind. Crops Prod. 53, 350-357.

Custódio, L., Patarra, J., Alberício, F., Neng, N.R., Nogueira, J.M.F., Romano, A., 2015. Phenolic composition, antioxidant potential and in vitro inhibitory activity of leaves and acorns of Quercus suber on key enzymes relevant for hyperglycemia and Alzheimer's disease. Ind. Crops Prod. 64, 45-51.

Deforce, K., Bastiaens, J., Calster, H.V., Vanhoutte, S., 2009. Iron age acorns from Boezing (Belgium): the role of acorn consumption in prehistory. Arch. Korresp. 39, 381-392.

Gea-Izquierdo, G., Cañellas, I., Montero, G., 2006. Acorn production in Spanish holm oak woodlands. Invest. Agric. Sist. Rec. For. 15, 339-354.

Heleno, S.A., Martins, A., Queiroz, M.J.R.P., Ferreira, I.C.F.R., 2015. Bioactivity of phenolic acids: metabolites vs. parent compounds. Food Chem. 173, 501-513.

INE. Estatísticas Agrícolas, 2013. Instituto Nacional de Estatística IP., 2014. Portugal ISBN: 978-989-25-0265-6.

ISO 12966-2,2011. Animal and vegetable fats and oils-Gas chromatography of fatty acid methyl esters - Part 2: Preparation of methyl esters of fatty acids. www.iso.org/iso/catalogue.

Islam, S., Shahid, M., Mohammad, F., 2013. Perspectives for natural product based agents derived from industrial plants in textile applications-a review. J. Clean Prod. 57, 2-18.

Lands, B., 2014. Historical perspectives on the impact of n-3 and n-6 nutrients on health. Prog. Lipid Res. 55, 17-29.

Li, H., Parry, J.W., 2011. Phytochemical compositions, antioxidant properties, and colon cancer antiproliferation effects of Turkish and Oregon hazelnut. Food Nutr. Sci. 2, 1142-1149.

Liao, W., Lai, T., Chen, L., Fu, J., Sreenivasan, S.T., Yu, Z., Ren, J., 2016. Synthesis and characterization of a walnut peptides-zinc complex and its antiproliferative activity against human breast carcinoma cells through the induction of apoptosis. J. Agric. Food Chem. 64, 1509-1519.

Lopes, I., Bernardo-Gil, M., 2005. Characterisation of acorn oils extracted by hexane and by supercritical carbon dioxide. J. Lipid Sci.Technol. 107, 12-19.

Nagata, M., Yamashita, I., 1992. Simple method for simultaneous determination of chlorophyll and carotenoids in tomato fruit. J. Jpn. Soc. Food Sci. Nutr. 39 925-928.

Ostertag, L.M., O’Kennedy, N., Horgan, G.W., Kroon, P.A., Duthie, G.G., Roos, B., 2011. In vitro anti-platelet effects of simple plant-derived phenolic compounds are only found at high, non-physiological concentrations. Mol. Nutr. Food Res. 55, 1624-1636.

Özcan, T., 2007. Characterization of Turkish Quercus L. taxa based on fatty acid compositions of the acorns. J. Am. Oil Chem. Soc. 84, 653-662.

Pandey, K.B., Rizvi, S.I., 2009. Plant polyphenols as dietary antioxidants in human health and disease. Oxid. Med. Cell. Longev. 2, 270-278.

Petrović, S., Šobajić, S., Rakić, S., Tomić, A., Kukić, J., 2004. Investigation of kernel oils of Quercus robur and Quercus cerris. Chem. Nat. Comp. 40, 420-422.

Rakić, S., Povrenović, D., Tešević, V., Simíc, M., Maletić, R., 2006. Oak acorn, polyphenols and antioxidant activity in functional food. J. Food Eng. 74, 416-423.

Rakić, S., Petrović, S., Kukić, J., Jadranin, M., Tešević, V., Povrenović, D. Šiler-Marinković, S., 2007. Influence of thermal treatment on phenolic compounds and antioxidant properties of oak acorns from Serbia. Food Chem. $104,830-834$

Rodrigues, F., Santos, J., Pimentel, F.B., Braga, N., Palmeira-de-Oliveira, A., Oliveira, M.B.P.P., 2015. Promising new applications of Castanea sativa shell: nutritional composition, antioxidant activity, amino acids and vitamin E profile. Food Funct. 6, 2854-2860.

Shahidi, F., Alasalvar, C., Liyana-Pathirana, C.M., 2007. Antioxidant phytochemicals in hazelnut kernel (Corylus avellana L.) and hazelnut byproducts. J. Agric. Food Chem. 55, 1212-1220.

Tejerina, D.S., García-Torres, M., Cabeza de Vaca, F.M., Vázquez, R.C., Cava, R., 2011. Acorns (Quercus rotundifolia Lam.) and grass as natural sources of antioxidants and fatty acids in the montanera feeding of Iberian pig: intra- and inter-annual variations. Food Chem. 124, 997-1004.

Vázquez, G., Fontenla, E., Santos, J., Freire, M.S., González-Álvarez, J., Antorrena, G., 2008. Antioxidant activity and phenolic content of chestnut (Castanea sativa) shell and eucalyptus (Eucalyptus globulus) bark extracts. Ind. Crops Prod. 28, 279-285.

Vasconcelos, M.C.B.M., Bennett, R.N., Rosa, E.A.S., Ferreira-Cardoso, J.V., 2010. Composition of European chestnut (Castanea sativa Mill.) and association with health effects: fresh and processed products. J. Agric. Food Chem. 90, 1578-1589.

Vinha, A.F., Alves, R.C., Barreira, S.V.P., Castro, A., Costa, A.S.G., Oliveira, M.B.P.P 2014. Effect of peel and seed removal on the nutritional value and antioxidant activity of tomato (Lycopersicon esculentum L.) fruits. LWT Food Sci. Technol. $55,197-202$. 